\title{
THE CONTROL OF PLASTID INHERITANCE IN PELARGONIUM ॥
}

\author{
R. A. E. TILNEY-BASSETT \\ Department of Genetics, University College of Swansea
}

Received 4.ii.72

\begin{abstract}
Summary
Clones of the Pelargonium cultivars Dolly Varden and Flower of Spring when used as female parent in $\mathrm{G} \times \mathrm{W}$ plastid crosses, give quite distinct segregation patterns. With D. Varden most offspring are green, rather less variegated and a few are white-type I pattern. With F. of Spring green and white offspring are approximately equally frequent and variegated few-type II pattern. There is considerable phenotypic variation within each pattern but no overlap between them.

The differences between the segregation patterns are related to differences in the female nuclear genotype, D. Varden is homozygous for the type I pattern and F. of Spring is heterozygous. Differences in the male nuclear genotype may slightly modify the segregation pattern but are unable to switch it from one type to another. It is suggested that the two patterns are controlled by alternative alleles of a nuclear gene, named $\operatorname{Pr}_{1}$ and $\operatorname{Pr}_{2}$, with an effect on plastid replication. It is further suggested that the major control of plastid inheritance is by the female parent, because the female produces the eggs, and the nuclear genotype of the eggs determines the behaviour of the plastids. Thus the $\operatorname{Pr}_{1}$ allele favours the replication of green plastids, and when all the eggs have this genotype a type I pattern results, whereas the $\operatorname{Pr}_{2}$ allele favours the replication of white plastids, and when about half the eggs have the $\operatorname{Pr}_{1}$ genotype and half the $\operatorname{Pr}_{2}$ genotype a type II pattern results. Unexpected deviations from simple monohybrid and backcross ratios are explained on the assumption that the $\operatorname{Pr}_{2}$ allele is lethal or semilethal, particularly on the female side, and particularly in combination with mutant plastids. The general demonstration of a nuclear control of the extranuclear plastid inheritance pattern is thought to have important implications for all studies of organelle genetics.
\end{abstract}

\section{InTRODUCTION}

ThE analysis of segregation patterns following crosses between Pelargonium cultivars containing green or white plastids in their germ layers showed that they were essentially the same with a constant female and varying male parent, but change the female and the pattern could be completely altered. Six different mutant females with two different constant green males could be arranged in a sequence in which white plastids were increasingly successful, and white and variegated embryos increasingly frequent. A similar sequence was demonstrated with three green females and two constant white males. It was concluded that the major control of plastid inheritance was determined by the female parent, with the male having only a minor, modifying influence even when male plastids were more successfully transmitted than female ones (Tilney-Bassett, 1970b). If the major cause of this variation between females was due to differences in the plastid, it appeared that there were at least three kinds of green and as many or more kinds of mutant plastid to account for. Alternatively, 
the evidence pointed towards a nuclear control of the variation in the pattern of plastid segregation. The experiments now to be described are an attempt to settle this question.

\section{Materials and Methods}

The two parental cultivars used in these experiments were the green (G) and white-over-green (W) clones of Flower of Spring (FS) and Dolly Varden (DV) described in an earlier report, where the methods of pollination and of scoring embryos were also explained (Tilney-Bassett, 1970a). The techniques of inbreeding and backcrossing with two kinds of plastid were entirely new and merit careful explanation:

Inbreds. Each cultivar was nuclear selfed and plastid crossed by pollinating the green plastid clone with the isogenic white male plastid clone of the same cultivar, or vice versa. For example:

$$
\begin{aligned}
& \text { FS G } \times W F S \text { and reciprocal FS W } \times \text { G FS } \\
& \text { DV G } \times W \text { DV and reciprocal DV W } \times \text { G DV. }
\end{aligned}
$$

When the seeds were germinated a mixture of green, variegated and white seedlings arose. The white seedlings died and the green were discarded. The variegated were chosen rather than green because then one could be certain that the original zygote had mixed plastids, and also because variegated seedlings were potential sources of both kinds of plastid in the same hybrid. The variegated seedlings were grown up until stable whiteover-green or pure green growing-points developed. The white-over-green chimeras contained mutant plastids in their germ layers just like their white-over-green parent. The green shoots contained only green plastids. The genetic behaviour of these inbred sister plants was then tested by crossing them as green females to the white-over-green parent as white male. For example:

$$
\begin{aligned}
& (\mathrm{FS} \mathrm{W} \times \mathrm{G} \mathrm{FS}) \mathrm{G} \times \mathrm{W} \mathrm{FS} \\
& (\mathrm{DV} \mathrm{G} \times \mathrm{W} \mathrm{DV}) \mathrm{G} \times \mathrm{W} \mathrm{DV} .
\end{aligned}
$$

The segregating progeny of sibs of these backcrossed inbreds was scored in 3-week-old embryos.

Hybrids. The two cultivars were crossed together in four possible ways according to the arrangement of plastids. For example:

$$
\begin{aligned}
& \text { FS G } \times W \text { DV and reciprocal DV W } \times \text { G FS } \\
& \text { DV G } \times W \text { FS and reciprocal FS } W \times G \text { DV. }
\end{aligned}
$$

In all four the nuclear cross is equivalent, whereas the plastid crosses vary. The seeds of these crosses were germinated and again only variegated seedlings retained. The variegated plants were grown up until the shoots had stabilised and could be used as a source of either green or white plastids. Only rarely did both types of plastid become available in different shoots of the same individual. In the bulk of the experiments the genetic behaviour of these sister hybrids was now tested by backcrossing to the white-overgreen parent of the same cultivar as the source of green plastids in the hybrid. In most cases the hybrid was used as the female parent. For example:

$(\mathrm{FS} \mathrm{G} \times \mathrm{W}$ DV) $\mathrm{G} \times \mathrm{W}$ FS and reciprocal $(\mathrm{DV} \mathrm{W} \times \mathrm{G} F \mathrm{~F}) \mathrm{G} \times \mathrm{W}$ FS. 
Only in a few cases were some hybrids used as males. For example:

$\mathrm{DV} \mathrm{G} \times \mathrm{W}(\mathrm{FS} \mathrm{W} \times \mathrm{G} \mathrm{DV})$ and reciprocal $\mathrm{DV} \mathrm{G} \times \mathrm{W}(\mathrm{DV} \mathrm{G} \times \mathrm{W} F \mathrm{~F})$.

It was not possible to test all the combinations of nuclear and plastid backcrosses. The segregating progeny of sibs of these backcrossed hybrids were scored in 3-week-old embryos.

In order to convert varying numbers of embryos into effective plastid contributions from the two parents, it is necessary to take account of the fact that variegated embryos contain plastids from both parents usually in disproportionate amounts. This is done by classifying variegated embryos into ten percentage groups according to their relative proportions of green and white tissues. Then, asuming that wholly green or wholly white embryos effectively received only one kind of plastid, an average of the relative numbers of green and white plastids received by the offspring can be determined.

In previous publications I have separated the data for good and bad embryos and given full fertility data. In this paper so much data is not very informative, so instead the results will be expressed as percentages of total embryos, a form in which the data can be most easily compared.

\section{Results}

\section{(i) Parental selfs and crosses}

Results of the parental nuclear selfs and crosses have already been published (Tilney-Bassett, 1970a). The $\mathrm{G} \times \mathrm{W}$ plastid crosses reveal two kinds of segregation pattern: When D. Varden is the green female parent, and either white F. of Spring or D. Varden the male, there are few white offspring, rather more variegated and the majority green. This pattern may be summarised as $\mathrm{G}>\mathrm{V}>\mathrm{W}$ (type I segregation pattern). When F. of Spring is the green female parent and either white F. of Spring or D. Varden the male parent, there are far fewer variegated than either white or green offspring, and the white and green occur in approximately equal frequency. This pattern may be summarised as $\mathrm{G}>\mathrm{V}<\mathrm{W}$ (type II segregation pattern).

The segregation pattern for the four $W \times G$ plastid crosses is of the $\mathrm{G}>\mathrm{V}>\mathrm{W}$ type. The pattern produced by $\mathrm{F}$. of Spring as female is therefore type II when the plastids are green and type I when the plastids are white, whereas with a female D. Varden the segregation pattern is type I with either green or white plastids.

\section{(ii) Inbred lines}

The plastid cross FS G $\times$ W FS was not used as a source of first generation inbred sibs because comparatively few variegated offspring are produced, instead all variegated progeny used were derived from the reciprocal FS $\mathrm{W} \times \mathrm{G}$ FS cross. Twenty-five variegated sibs were tested as females and were found to consist of 14 type I and 11 type II plants (table 1). Seventeen variegated sibs from both $D$. Varden inbreds were tested as females and were found to consist of type I plants only (table 2). Within each segregation pattern there is apparently a continuous variation with no overlap between the patterns. Although one can point to plants from the type I class producing fewer green offspring than some examples from 
TABLE 1

Percentages of total embryos and the corresponding estimate for the average percentage contribution of green plastids

Pure green shoots of variegated first-generation selfs backcrossed to white F. of Spring

Self: White F. of Spring female by green F. of Spring male

Sibs arranged in order of

percentage green plastid contribution

(FS W $\times$ G FS/5) $\mathrm{G} \times \mathrm{W}$ FS

(FS W $\times$ G FS $/ 9$ )

$(\mathrm{FS} \mathrm{W} \times \mathrm{G} \mathrm{FS} / 2$ )

$($ FS W $\times$ G FS/17)

$(\mathrm{FS} \mathrm{W} \times \mathrm{G} \mathrm{FS} / 4$ )

$(\mathrm{FS} \mathrm{W} \times \mathrm{G} \mathrm{FS} / 7$ )

$($ FS W $\times$ G FS/20)

$($ FS W $\times$ G FS/13)

$(\mathrm{FS} \mathrm{W} \times \mathrm{G} \mathrm{FS} / 16)$

$(\mathrm{FS} \mathrm{W} \times \mathrm{G} \mathrm{FS} / 23$ )

$($ FS W $\times$ G FS/14)

$(\mathrm{FS} \mathrm{W} \times \mathrm{GFS} / 12$ )

$($ FS W $\times$ G FS/31)

$($ FS W $\times$ G FS/11)

$(\mathrm{FS} \mathrm{W} \times \mathrm{G} \mathrm{FS} / 10$ )

(FS W $\times$ G FS $/ 3$ )

$($ FS W $\times$ G FS/29)

$(\mathrm{FS} \mathrm{W} \times \mathrm{G} \mathrm{FS} / 26)$

$($ FS W $\times$ G FS/22)

(FS W $\times$ G FS $/ 8$ )

$($ FS W $\times$ G FS) $/ 27$

$($ FS W $\times$ G FS/25)

$($ FS W $\times$ G FS/15)

$(\mathrm{FS} \mathrm{W} \times \mathrm{G} \mathrm{FS} / 6$ )

$($ FS $\mathrm{W} \times \mathrm{G} \mathrm{FS} / 19)$

\begin{tabular}{|c|c|c|c|c|c|}
\hline \multicolumn{4}{|c|}{ Percentage embryos } & \multirow{2}{*}{$\begin{array}{c}\text { Percentage } \\
\text { green } \\
\text { plastids }\end{array}$} & \multirow{2}{*}{$\begin{array}{c}\text { Segregation } \\
\text { pattern } \\
\text { type }\end{array}$} \\
\hline $\mathrm{G}$ & V & W & Total & & \\
\hline $100 \cdot 0$ & 一 & - & 119 & $100 \cdot 0$ & I \\
\hline $100 \cdot 0$ & - & - & 61 & $100 \cdot 0$ & I \\
\hline $100 \cdot 0$ & - & - & 41 & $100 \cdot 0$ & I \\
\hline 98.9 & $1 \cdot 1$ & - & 95 & 99.9 & I \\
\hline $97 \cdot 6$ & $2 \cdot 4$ & - & 84 & $99 \cdot 7$ & I \\
\hline $94 \cdot 2$ & $5 \cdot 8$ & - & 104 & $99 \cdot 4$ & I \\
\hline $97 \cdot 9$ & $2 \cdot 1$ & - & 96 & $99 \cdot 4$ & I \\
\hline $95 \cdot 3$ & $3 \cdot 9$ & $0 \cdot 8$ & 129 & $98 \cdot 6$ & I \\
\hline $97 \cdot 4$ & $1 \cdot 3$ & $1 \cdot 3$ & 77 & $97 \cdot 9$ & I \\
\hline $91 \cdot 0$ & $8 \cdot 2$ & 0.8 & 122 & $97 \cdot 9$ & I \\
\hline 94.5 & $3 \cdot 7$ & $1 \cdot 8$ & 109 & $97 \cdot 6$ & I \\
\hline 94.7 & $3 \cdot 5$ & $1 \cdot 8$ & 57 & $96 \cdot 8$ & I \\
\hline $78 \cdot 1$ & $17 \cdot 2$ & $4 \cdot 7$ & 128 & $91 \cdot 5$ & I \\
\hline $75 \cdot 3$ & $17 \cdot 6$ & $7 \cdot 1$ & 85 & $90 \cdot 2$ & I \\
\hline $75 \cdot 4$ & 一 & $24 \cdot 6$ & 57 & $75 \cdot 4$ & II \\
\hline $72 \cdot 5$ & $2 \cdot 5$ & $25 \cdot 0$ & 40 & $74 \cdot 8$ & II \\
\hline $70 \cdot 5$ & - & $29 \cdot 5$ & 78 & $70 \cdot 5$ & II \\
\hline $64 \cdot 9$ & $5 \cdot 4$ & $29 \cdot 7$ & 74 & 68.9 & II \\
\hline $68 \cdot 0$ & - & $32 \cdot 0$ & 25 & $68 \cdot 0$ & II \\
\hline $59 \cdot 7$ & 0.8 & $39 \cdot 5$ & 129 & $59 \cdot 8$ & II \\
\hline $56 \cdot 7$ & $3 \cdot 0$ & $40 \cdot 3$ & 67 & $59 \cdot 6$ & II \\
\hline $55 \cdot 4$ & $3 \cdot 8$ & $40 \cdot 8$ & 184 & $57 \cdot 9$ & II \\
\hline 53.5 & $2 \cdot 0$ & $44 \cdot 5$ & 101 & 54.9 & II \\
\hline $51 \cdot 7$ & - & $48 \cdot 3$ & 60 & $51 \cdot 8$ & II \\
\hline $40 \cdot 0$ & $3 \cdot 6$ & $56 \cdot 4$ & 55 & $42 \cdot 1$ & II \\
\hline
\end{tabular}

TABLE 2

Percentages of total embryos and the corresponding estimate for the average percentage contribution of green plastids

Pure green shoots of variegated first-generation selfs backcrossed to white D. Varden Self: Green D. Varden female by white D. Varden male

Sibs arranged in order of percentage green plastid contribution

$(\mathrm{DV} G \times \mathrm{W} D V / 3) \mathrm{G} \times \mathrm{W}$ DV

$(\mathrm{DV}$ G $\times$ W DV/1)

$(\mathrm{DV} G \times \mathrm{W}$ DV/7)

$(\mathrm{DV} G \times \mathrm{W}$ DV/8)

$($ DV G $\times$ W DV/6)

$(\mathrm{DV} \mathrm{G} \times \mathrm{W} \mathrm{DV} / 9)$

$(\mathrm{DV} \mathrm{G} \times \mathrm{W} \mathrm{DV} / 5)$

$(\mathrm{DV}$ G $\times$ W DV/4)

$(\mathrm{DV} G \times \mathrm{W}$ DV/10)

$(\mathrm{DV} \mathrm{G} \times \mathrm{W} \mathrm{DV} / 2$ )
Percentage embryos

\begin{tabular}{cccc}
\hline$G$ & $V$ & W & Total \\
$88 \cdot 4$ & $11 \cdot 2$ & $0 \cdot 4$ & 232 \\
$84 \cdot 9$ & $15 \cdot 1$ & - & 139 \\
$75 \cdot 7$ & $23 \cdot 9$ & $0 \cdot 4$ & 230 \\
$82 \cdot 5$ & $15 \cdot 3$ & $2 \cdot 2$ & 223 \\
$69 \cdot 6$ & $24 \cdot 6$ & $5 \cdot 8$ & 240 \\
$61 \cdot 7$ & $33 \cdot 6$ & $4 \cdot 7$ & 253 \\
$55 \cdot 8$ & $34 \cdot 7$ & $9 \cdot 5$ & 95 \\
$60 \cdot 4$ & $29 \cdot 5$ & $10 \cdot 1$ & 268 \\
$54 \cdot 9$ & $32 \cdot 4$ & $12 \cdot 7$ & 244 \\
$55 \cdot 1$ & 33.7 & $11 \cdot 2$ & 214
\end{tabular}

$\begin{array}{cc}\begin{array}{c}\text { Percentage } \\ \text { green } \\ \text { plastids }\end{array} & \begin{array}{c}\text { Segregation } \\ \text { pattern } \\ \text { type }\end{array} \\ 97 \cdot 6 & \text { I } \\ 96 \cdot 5 & \text { I } \\ 96 \cdot 4 & \text { I } \\ 93 \cdot 3 & \text { I } \\ 86 \cdot 7 & \text { I } \\ 82 \cdot 7 & \text { I } \\ 82 \cdot 6 & \text { I } \\ 79 \cdot 7 & \text { I } \\ 77.5 & \text { I } \\ 73.5 & \text { I }\end{array}$

Self: White D. Varden female by green D. Varden male

\begin{tabular}{|c|c|c|c|c|}
\hline $\mathrm{VW} \times \mathrm{GDV} / 3) \mathrm{G} \times$ & $85 \cdot 7$ & $14 \cdot 3$ & - & 84 \\
\hline$(\mathrm{DV} W \times \mathrm{G} D V / 2)$ & $77 \cdot 3$ & $19 \cdot 6$ & $3 \cdot 1$ & 255 \\
\hline $\mathrm{DV} W \times \mathrm{G}$ DV $/ 7)$ & $53 \cdot 0$ & $41 \cdot 3$ & $5 \cdot 7$ & 247 \\
\hline $\mathrm{DV} W \times \mathrm{G} D V / 4)$ & $55 \cdot 2$ & $36 \cdot 2$ & $8 \cdot 6$ & 279 \\
\hline$W \times G \mathrm{DV} / 5)$ & $54 \cdot 5$ & $29 \cdot 0$ & $16 \cdot 5$ & 145 \\
\hline$V \mathrm{~W} \times \mathrm{G} \mathrm{DV} / 1)$ & 34 & $49 \cdot 6$ & $16 \cdot 3$ & 258 \\
\hline $\mathrm{W} \times \mathrm{G} \mathrm{DV} / 6)$ & $40 \cdot 7$ & $39 \cdot 8$ & $19 \cdot 5$ & 113 \\
\hline
\end{tabular}

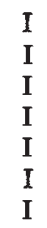


the type II, there is really no overlap, because the type I plants also produce a high frequency of variegated with fewer white, and the type II plants a high frequency of white with few variegated embryos. The variation within each segregation pattern can also be displayed as a histogram (figs. 1 and 2). The type I pattern gives a skewed distribution running into the 100 per cent. green plastid contribution. This is particularly conspicuous for the F. of Spring inbred lines, which have less variance than the D. Varden families. The type II pattern, shown by some F. of Spring families, gives a normal looking distribution.

\section{(iii) Hybrid lines}

A previous set of experiments demonstrated the importance of the female parent in controlling the segregation pattern (Tilney-Bassett, 1970b). This rule is confirmed by testing a few of the $F_{1}$ hybrids, as males, in backcrosses to their parents, as females, using the hybrids, sometimes as a source of white, sometimes as a source of green plastids. For each backcross, the results are compared with the equivalent parental plastid cross (table 3 ).

TABLE 3

Percentages of total embryos and the corresponding estimate for the average percentage contribution of green plastids

Pure green shoots or white-over-green chimera shoots of variegated $F_{1}$ hybrids used as males backcrossed to parental cultivars, and compared with original parental crosses of same plastid constitution

\begin{tabular}{|c|c|c|c|c|c|c|}
\hline \multirow{2}{*}{$\begin{array}{l}\text { Sibs arranged in order of } \\
\text { percentage green plastid } \\
\text { contribution }\end{array}$} & \multicolumn{4}{|c|}{ Percentage embryos } & \multirow{2}{*}{$\begin{array}{l}\text { Percentage } \\
\text { green } \\
\text { plastids }\end{array}$} & \multirow{2}{*}{$\begin{array}{l}\text { Segregation } \\
\text { pattern } \\
\text { type }\end{array}$} \\
\hline & G & V & W & Total & & \\
\hline FS $\mathrm{G} \times \mathrm{W}$ FS & $45 \cdot 8$ & $7 \cdot 2$ & $47 \cdot 0$ & 1497 & $51 \cdot 2$ & II \\
\hline $\mathrm{FS} \mathrm{G} \times W(\mathrm{DV} \mathrm{G} \times \mathrm{W} \mathrm{FS} / 1)$ & $49 \cdot 3$ & $3 \cdot 4$ & $47 \cdot 3$ & 404 & $51 \cdot 8$ & II \\
\hline $\mathrm{DV} \mathrm{G} \times \mathrm{W} \mathrm{FS}$ & $70 \cdot 9$ & $18 \cdot 9$ & $10 \cdot 2$ & 581 & 83.3 & I \\
\hline $\mathrm{DV} G \times \mathrm{W}(\mathrm{DV} G \times \mathrm{W} F S / 1)$ & $85 \cdot 4$ & $10 \cdot 4$ & $4 \cdot 2$ & 403 & $92 \cdot 2$ & I \\
\hline $\mathrm{DV} \mathrm{G} \times \mathrm{W}(\mathrm{DV} \mathrm{G} \times \mathrm{W} \mathrm{FS} / 5)$ & $70 \cdot 4$ & $25 \cdot 0$ & $4 \cdot 6$ & 44 & $86 \cdot 9$ & I \\
\hline $\mathrm{DV} \mathrm{G} \times \mathrm{W}(\mathrm{DV} \mathrm{G} \times \mathrm{W} \mathrm{FS} / 6)$ & $69 \cdot 5$ & $27 \cdot 6$ & $2 \cdot 9$ & 105 & $86 \cdot 3$ & I \\
\hline $\mathrm{DV} G \times \mathrm{W}(\mathrm{FS} \mathrm{W} \times \mathrm{G} \mathrm{DV} / 1)$ & $80 \cdot 4$ & $16 \cdot 7$ & $2 \cdot 9$ & 174 & $92 \cdot 9$ & $\mathbf{I}$ \\
\hline FS W $\times$ G FS & $73 \cdot 6$ & $21 \cdot 6$ & $4 \cdot 8$ & 927 & $88 \cdot 4$ & I \\
\hline $\mathrm{FS} \mathrm{W} \times \mathrm{G}(\mathrm{FS} \mathrm{G} \times \mathrm{W} \mathrm{DV} / 1)$ & $73 \cdot 7$ & $22 \cdot 6$ & $3 \cdot 7$ & 349 & $90 \cdot 3$ & I \\
\hline $\mathrm{DV} W \times \mathrm{GFS}$ & $59 \cdot 5$ & $29 \cdot 8$ & $10 \cdot 7$ & 662 & $75 \cdot 8$ & I \\
\hline $\mathrm{DV} \mathrm{W} \times \mathrm{G}(\mathrm{FS} \mathrm{G} \times \mathrm{W} \mathrm{DV} / 1)$ & $48 \cdot 7$ & $38 \cdot 0$ & $13 \cdot 3$ & 339 & $68 \cdot 9$ & I \\
\hline $\mathrm{DV} W \times \mathrm{G} D V$ & $58 \cdot 0$ & $35 \cdot 0$ & $7 \cdot 0$ & 2259 & $80 \cdot 0$ & I \\
\hline $\mathrm{DV} W \times \mathrm{G}(\mathrm{DV} G \times \mathrm{W} F S / 4)$ & $48 \cdot 1$ & $42 \cdot 6$ & $9 \cdot 3$ & 54 & $71 \cdot 1$ & I \\
\hline $\mathrm{DV} W \times \mathrm{G}(\mathrm{DV} \mathrm{G} \times \mathrm{W} \mathrm{FS} / 3)$ & $44 \cdot 9$ & $47 \cdot 6$ & $7 \cdot 5$ & 107 & $69 \cdot 3$ & I \\
\hline $\mathrm{DV} W \times \mathrm{G}(\mathrm{FS} \mathrm{W} \times \mathrm{G} \mathrm{DV} / 2)$ & $48 \cdot 7$ & $41 \cdot 0$ & $10 \cdot 3$ & 78 & $68 \cdot 5$ & I \\
\hline $\mathrm{DV} W \times \mathrm{G}(\mathrm{FS} \mathrm{W} \times \mathrm{G} \mathrm{DV} / 3)$ & $44 \cdot 2$ & $43 \cdot 3$ & $12 \cdot 5$ & 104 & $65 \cdot 1$ & I \\
\hline
\end{tabular}

The segregation pattern of the backcross corresponds to the parental plastid cross in every case. The importance of the female parent is particularly stressed in two sets of crosses where the same hybrid male is used against two different females. The cross FS G $\times W(D V G \times W$ FS/1) gives a type II pattern, like the parental FS G $\times$ W FS cross, yet the cross DV G $\times W$ $(\mathrm{DV}$ G $\times \mathrm{WFS} / \mathrm{l})$ gives a type I pattern, like the parental DV G $\times$ W FS cross. Hence a change in the female completely switches the segregation 


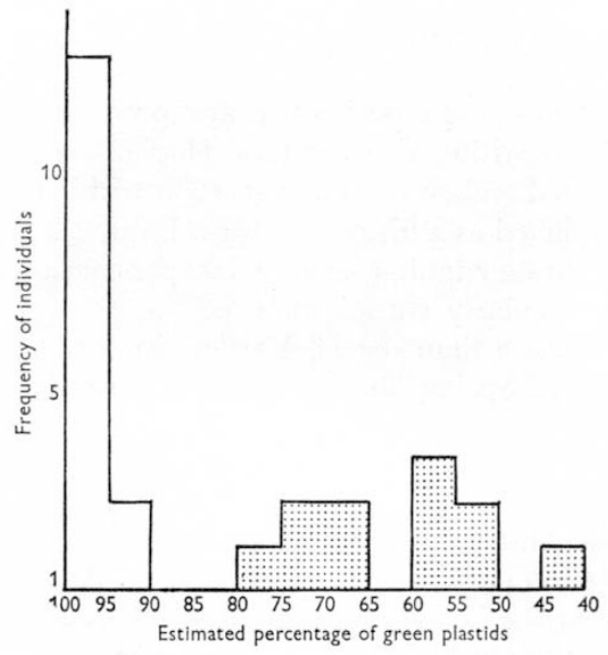

FIG. 1.-(FS W $\times$ G FS) G $\times$ W FS.

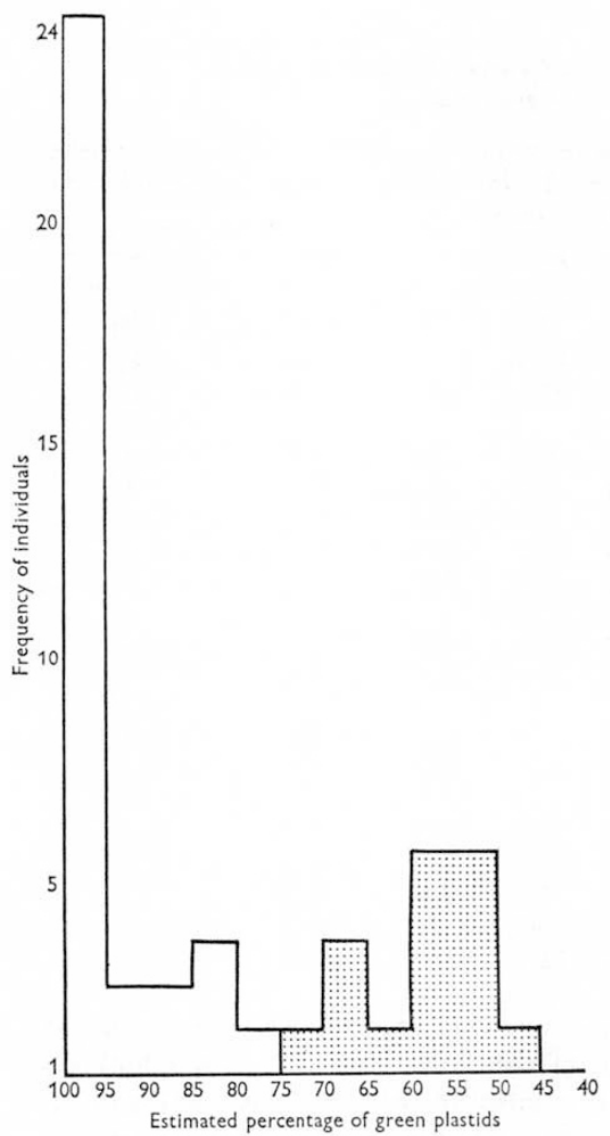

Frg. 3.-(FS G $\times$ W DV) $\mathrm{G} \times \mathrm{W}$ FS $(D V W \times G F S) G \times$ W FS.

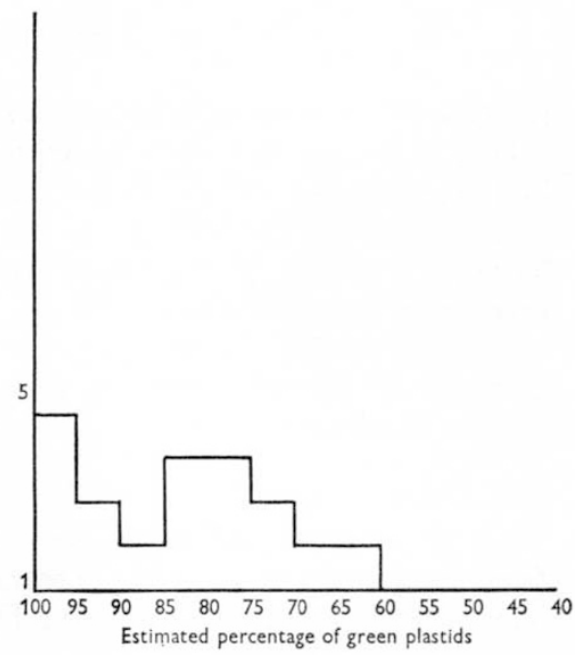

FIG. 2.-(DV G $\times$ W DV) $G \times W D V$ $(D V W \times G$ DV) $G \times W$ DV.
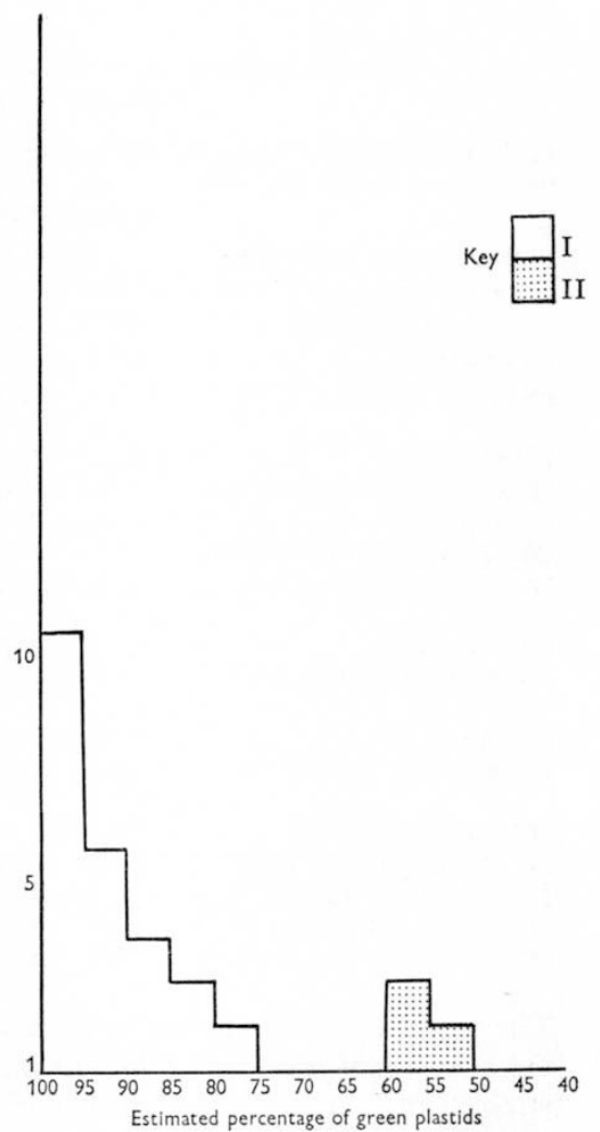

FIG. 4.-(DV G $\times$ W FS) G $\times$ W DV $($ FS W $\times$ G DV) $\mathrm{G} \times \mathrm{W}$ DV.

FIGs. 1-4.-Histograms showing the relationship between frequency of individuals, their segregation pattern, and the effective transmission of green plastids, in 5 per cent. intervals. 
pattern even in the presence of a constant hybrid male. Another paired comparison is between alternative white females and a constant green hybrid male. The cross $F S \mathrm{~W} \times \mathrm{G}(\mathrm{FS} \mathrm{G} \times \mathrm{W} \mathrm{DV} / \mathrm{l})$ gives a type I pattern similar to FS $\times$ F FS, whereas the cross $D V W \times G(F S G \times W D V / 1)$ gives a type I pattern similar to $\mathrm{DV} W \times \mathrm{GFS}$; this is unlikely to be due to coincidence since although the two pairs of crosses have the same segregation pattern type they are some distance apart. These results vindicate the major control by the female parent in determining the segregation pattern of the offspring, and for this reason the hybrids were now tested extensively as females.

The results of the hybrid backcrosses are separated according to the direction and plastid constitution of the parental crosses (tables 4-7). Three of the group of sibs tested contain examples of hybrids that give rise to

TABLE 4

Percentages of total embryos and the corresponding estimate for the average percentage contribution of green plastids

Pure green shoot of variegated $\mathrm{F}_{1}$ hybrids backcrossed to white F. of Spring Hybrid: Green F. of Spring female by white D. Varden male

Sibs arranged in order of percentage green plastid contribution

$(\mathrm{FS} \mathrm{G} \times \mathrm{W} \mathrm{DV} / 8) \mathrm{G} \times \mathrm{W} \mathrm{FS}$

(FS G $\times$ W DV/13)

$(\mathrm{FS} \mathrm{G} \times \mathrm{W} \mathrm{DV} / 10$ )

$(\mathrm{FS} \mathrm{G} \times \mathrm{W} \mathrm{DV} / 7)$

$($ FS G $\times$ W DV/9)

(FS G $\times$ W DV/12)

$(F S$ G $\times W D V / 5)$

$(\mathrm{FS} \mathrm{G} \times \mathrm{W} \mathrm{DV} / 11)$

$(\mathrm{FS} \mathrm{G} \times \mathrm{W} \mathrm{DV} / 4$ )

$($ FS G $\times$ W DV/1)

$(\mathrm{FS} \mathrm{G} \times \mathrm{WDV} / 3$ )

$($ FS G $\times$ W DV $/ 6$ )

$(\mathrm{FS} \mathrm{G} \times \mathrm{W} \mathrm{DV} / 2)$

\begin{tabular}{cccr}
\multicolumn{4}{c}{ Percentage embryos } \\
\hline G & V & W & Total \\
99.2 & 0.8 & - & 240 \\
98.4 & 1.6 & - & 187 \\
98.6 & 0.7 & 0.7 & 144 \\
96.7 & $2 \cdot 9$ & 0.4 & 275 \\
94.2 & $5 \cdot 8$ & - & 260 \\
92.5 & 6.3 & 1.2 & 254 \\
90.7 & $8 \cdot 8$ & 0.5 & 215 \\
89.6 & $7 \cdot 8$ & 2.6 & 154 \\
83.1 & 15.4 & 1.5 & 266 \\
82.0 & 16.5 & 1.5 & 273 \\
82.6 & 15.1 & 2.3 & 259 \\
64.5 & 27.7 & 7.8 & 245 \\
52.2 & - & 47.8 & 115
\end{tabular}

both type I and type II patterns. The exception is the group of sibs from the cross FS W $\times$ G DV (table 7), but only 12 plants were tested and I believe there is no reason to regard this cross as truly different from the others.

Comparisons of the data show two significant effects:

(1) Either segregation pattern can be produced when the green female plastids are derived from either cultivar, indicating that there is no difference between their green plastids in this respect.

(2) Of the 19 type II patterns (tables 4-7) only one was derived from an $\mathrm{F}_{1}$ hybrid in which $\mathrm{F}$. of Spring, the source of the type II pattern, had been the female parent; in the other 18 hybrids F. of Spring had been the male parent and carrying green plastids more frequently than white ones. This suggests that the direction of the parental crosses may have an unexpected influence on the relative frequencies of the possible hybrid genotypes.

The segregation data for individual families reveals the same kind of continuous variation within each pattern as for the inbred lines (figs. 3-4). 
The $\mathrm{F}_{1}$ hybrid $(\mathrm{FS} \mathrm{G} \times \mathrm{WDV} / 1) \mathrm{G}$ gave an estimated green plastid contribution of 95 per cent. with white male F. of Spring compared with 83 per cent. with D. Varden, demonstrating the greater success of the white D. Varden plastids. The same trend is apparent when one compares all the hybrid families in backcrosses to white F. of Spring or white D. Varden.

TABLE 5

Percentages of total embryos and the corresponding estimate for the average percentage contribution of green plastids

Pure green shoots of variegated $F_{1}$ hybrids backcrossed to white $F$. of Spring Hybrid: White D. Varden female by green F. of Spring male

\begin{tabular}{|c|c|c|c|c|c|c|}
\hline \multirow{2}{*}{$\begin{array}{l}\text { Sibs arranged in order of } \\
\text { percentage green plastid } \\
\text { contribution }\end{array}$} & \multicolumn{4}{|c|}{ Percentage embryos } & \multirow{2}{*}{$\begin{array}{c}\text { Percentage } \\
\text { green } \\
\text { plastids }\end{array}$} & \multirow{2}{*}{$\begin{array}{l}\text { Segregation } \\
\text { pattern } \\
\text { type }\end{array}$} \\
\hline & $\mathrm{G}$ & $\mathrm{V}$ & $\mathrm{W}$ & Total & & \\
\hline$(\mathrm{DV} W \times \mathrm{G} F S / 20) \mathrm{G} \times \mathrm{W} F S$ & $99 \cdot 6$ & $0 \cdot 4$ & 一 & 232 & $99 \cdot 9$ & I \\
\hline$(\mathrm{DV} W \times \mathrm{GFS} / 9)$ & $99 \cdot 5$ & $0 \cdot 5$ & - & 206 & $99 \cdot 9$ & I \\
\hline$(\mathrm{DV} W \times \mathrm{G} F \mathrm{~F} / 10)$ & $98 \cdot 7$ & $1 \cdot 3$ & - & 313 & $99 \cdot 8$ & I \\
\hline$(\mathrm{DV} W \times \mathrm{GFS} / 26)$ & $99 \cdot 1$ & 0.9 & - & 226 & $99 \cdot 6$ & I \\
\hline$(\mathrm{DV} W \times \mathrm{G} F \mathrm{~F} / 25)$ & $96 \cdot 4$ & $3 \cdot 6$ & - & 110 & $99 \cdot 6$ & I \\
\hline$(\mathrm{DV} W \times \mathrm{G} F \mathrm{~F} / 11)$ & $95 \cdot 7$ & $4 \cdot 3$ & - & 186 & $99 \cdot 6$ & I \\
\hline$(\mathrm{DV} W \times \mathrm{G} F \mathrm{~F} / 13)$ & $95 \cdot 1$ & $4 \cdot 9$ & - & 143 & $99 \cdot 5$ & I \\
\hline$(\mathrm{DV} W \times \mathrm{G} F \mathrm{~F} / 24)$ & $94 \cdot 4$ & $5 \cdot 6$ & - & 90 & $99 \cdot 4$ & I \\
\hline$(\mathrm{DV} W \times \mathrm{G} F \mathrm{~S} / 4)$ & $91 \cdot 2$ & $8 \cdot 8$ & - & 193 & $98 \cdot 1$ & I \\
\hline$(\mathrm{DV} W \times \mathrm{G} F \mathrm{~F} / 8)$ & $92 \cdot 2$ & $6 \cdot 7$ & $1 \cdot 1$ & 282 & $98 \cdot 0$ & I \\
\hline$(\mathrm{DV} W \times \mathrm{G} F \mathrm{~S} / 22)$ & $95 \cdot 1$ & 3.7 & $1 \cdot 2$ & 243 & 97.9 & I \\
\hline$(\mathrm{DV} W \times \mathrm{GFS} / 12)$ & $91 \cdot 8$ & $7 \cdot 7$ & 0.5 & 219 & $97 \cdot 7$ & I \\
\hline$(\mathrm{DV} W \times \mathrm{GFS} / 17)$ & $95 \cdot 7$ & $1 \cdot 8$ & $2 \cdot 5$ & 282 & $97 \cdot 4$ & I \\
\hline$(\mathrm{DV} W \times \mathrm{G} F S / 35)$ & $92 \cdot 6$ & $6 \cdot 1$ & $1 \cdot 3$ & 230 & $97 \cdot 4$ & I \\
\hline$(\mathrm{DV} W \times \mathrm{G} F \mathrm{~S} / 27)$ & $81 \cdot 6$ & $15 \cdot 0$ & $3 \cdot 4$ & 147 & $93 \cdot 2$ & I \\
\hline$(\mathrm{DV} W \times \mathrm{GFS} / 5)$ & $70 \cdot 0$ & 23.9 & $6 \cdot 1$ & 230 & $86 \cdot 4$ & I \\
\hline$(\mathrm{DV} W \times \mathrm{GFS} / 14)$ & $72 \cdot 6$ & $18 \cdot 4$ & $9 \cdot 0$ & 212 & $85 \cdot 8$ & I \\
\hline$(\mathrm{DV} W \times \mathrm{GFS} / 3)$ & $69 \cdot 1$ & $21 \cdot 5$ & $9 \cdot 4$ & 233 & $84 \cdot 6$ & I \\
\hline$(\mathrm{DV} W \times \mathrm{G} F \mathrm{~S} / 19)$ & $55 \cdot 6$ & $37 \cdot 3$ & $7 \cdot 1$ & 212 & $80 \cdot 2$ & I \\
\hline$(\mathrm{DV} W \times \mathrm{G} \mathrm{FS} / 7)$ & $63 \cdot 4$ & $23 \cdot 5$ & $13 \cdot 1$ & 145 & $77 \cdot 5$ & I \\
\hline$(\mathrm{DV} W \times \mathrm{G} F \mathrm{~S} / 18)$ & $73 \cdot 1$ & - & $26 \cdot 9$ & 223 & $73 \cdot 1$ & II \\
\hline$(\mathrm{DV} W \times \mathrm{G} F S / 2)$ & 63.6 & $2 \cdot 9$ & $33 \cdot 5$ & 176 & $66 \cdot 3$ & II \\
\hline$(\mathrm{DV} W \times \mathrm{G} F S / 31)$ & $59 \cdot 2$ & $9 \cdot 1$ & $31 \cdot 7$ & 120 & $65 \cdot 7$ & II \\
\hline$(\mathrm{DV} W \times \mathrm{G} F \mathrm{~F} / 29)$ & $58 \cdot 3$ & $10 \cdot 4$ & $31 \cdot 3$ & 163 & $65 \cdot 3$ & II \\
\hline$(\mathrm{DV} W \times \mathrm{G} \mathrm{FS} / 6)$ & $60 \cdot 0$ & $5 \cdot 0$ & $35 \cdot 0$ & 160 & $63 \cdot 3$ & II \\
\hline$(\mathrm{DV} W \times \mathrm{G} F \mathrm{~S} / 38)$ & $54 \cdot 9$ & $8 \cdot 0$ & $37 \cdot 1$ & 224 & $59 \cdot 6$ & II \\
\hline$(\mathrm{DV} W \times \mathrm{G} F \mathrm{~F} / 36)$ & $56 \cdot 8$ & $3 \cdot 3$ & $39 \cdot 9$ & 273 & $59 \cdot 1$ & II \\
\hline$(\mathrm{DV} W \times \mathrm{G} F \mathrm{~S} / 21)$ & $58 \cdot 3$ & - & $41 \cdot 7$ & 48 & $58 \cdot 3$ & II \\
\hline$(\mathrm{DV} W \times \mathrm{G} F \mathrm{~S} / 33)$ & 54.5 & $6 \cdot 4$ & $39 \cdot 1$ & 110 & $58 \cdot 3$ & II \\
\hline$(\mathrm{DV} W \times \mathrm{G} F \mathrm{~F} / 15)$ & $53 \cdot 2$ & $2 \cdot 4$ & $44 \cdot 4$ & 248 & $55 \cdot 2$ & II \\
\hline$(\mathrm{DV} W \times \mathrm{G} F \mathrm{~S} / 23)$ & $54 \cdot 5$ & - & $45 \cdot 5$ & 55 & $54 \cdot 5$ & II \\
\hline$(\mathrm{DV} W \times \mathrm{G} F S / 37)$ & $52 \cdot 5$ & $3 \cdot 0$ & $44 \cdot 5$ & 101 & $54 \cdot 5$ & II \\
\hline$(\mathrm{DV} W \times \mathrm{GFS} / 1)$ & $53 \cdot 2$ & 0.9 & $45 \cdot 9$ & 109 & $54 \cdot 0$ & II \\
\hline$(\mathrm{DV} W \times \mathrm{G} F \mathrm{~S} / 28)$ & $51 \cdot 5$ & $2 \cdot 3$ & $46 \cdot 2$ & 130 & $52 \cdot 6$ & II \\
\hline$(\mathrm{DV} W \times \mathrm{G} F \mathrm{~F} / 30)$ & $44 \cdot 6$ & $0 \cdot 9$ & $54 \cdot 5$ & 110 & $45 \cdot 2$ & II \\
\hline
\end{tabular}

The data also show that this general lowering in the frequency of green embryos with a D. Varden male is due to the rise in variegated embryos and not to any raising of white ones. This is also true for the type II patterns. Similar effects were observed before (Tilney-Bassett, 1970b). Together they show that plastids carried by the male are more effectively transmitted to the progeny by D. Varden than by F. of Spring, whether the plastids are green or white. Hence the modifying effect of the male is 
constant for the cultivar, apparently irrespective of the plastid colour, green or white, normal or mutant. It thus seems probable that the modifying effect of the male on the segregation pattern is controlled by its nuclear rather than by its plastid genotype, just as the major control of the segregation pattern is controlled by the female nuclear rather than by its plastid

\section{TABLE 6}

Percentages of total embryos and the corresponding estimate for the average percentage contribution of green plastids

Pure green shoots of variegated $F_{1}$ hybrids backcrossed to white $D$. Varden Hybrid: Green D. Varden female by white F. of Spring male

\begin{tabular}{|c|c|c|c|c|c|c|}
\hline \multirow{2}{*}{$\begin{array}{l}\text { Sibs arranged in order of } \\
\text { percentage green plastid } \\
\text { contribution }\end{array}$} & \multicolumn{4}{|c|}{ Percentage embryos } & \multirow{2}{*}{$\begin{array}{l}\text { Percentage } \\
\text { green } \\
\text { plastids }\end{array}$} & \multirow{2}{*}{$\begin{array}{l}\text { Segregation } \\
\text { pattern } \\
\text { type }\end{array}$} \\
\hline & G & $\mathrm{V}$ & $\mathrm{W}$ & Total & & \\
\hline$(\mathrm{DV} \mathrm{G} \times \mathrm{WFS} / 14) \mathrm{G} \times \mathrm{WDV}$ & $98 \cdot 8$ & $1 \cdot 2$ & - & 241 & $99 \cdot 9$ & I \\
\hline$(\mathrm{DV} \mathrm{G} \times \mathrm{W} \mathrm{FS} / \mathrm{l})$ & $82 \cdot 0$ & $17 \cdot 2$ & 0.8 & 122 & $96 \cdot 2$ & I \\
\hline$(\mathrm{DV} G \times \mathrm{W} F \mathrm{FS} / 12)$ & $79 \cdot 2$ & $20 \cdot 8$ & - & 202 & $96 \cdot 1$ & I \\
\hline$(\mathrm{DV} \mathrm{G} \times \mathrm{W} \mathrm{FS} / 9)$ & $76 \cdot 8$ & $23 \cdot 0$ & 0.2 & 383 & $95 \cdot 9$ & I \\
\hline$(\mathrm{DV} \mathrm{G} \times \mathrm{W}$ FSIO) & $84 \cdot 8$ & $15 \cdot 2$ & - & 79 & $95 \cdot 5$ & I \\
\hline$(\mathrm{DV} \mathrm{G} \times \mathrm{W} \mathrm{FS} / 6)$ & $69 \cdot 8$ & $29 \cdot 1$ & $1 \cdot 1$ & 189 & $92 \cdot 7$ & I \\
\hline$(\mathrm{DV} G \times \mathrm{W} F \mathrm{~S} / 15)$ & $71 \cdot 9$ & $27 \cdot 0$ & $1 \cdot 1$ & 267 & $9 \mathrm{I} \cdot \mathrm{I}$ & I \\
\hline$(\mathrm{DV} \mathrm{G} \times \mathrm{W} \mathrm{FS} / 7)$ & $42 \cdot 8$ & $53 \cdot 4$ & $3 \cdot 8$ & 208 & $82 \cdot 7$ & I \\
\hline$(\mathrm{DV} \mathrm{G} \times \mathrm{W} \mathrm{FS} / 8$ ) & $48 \cdot 1$ & $45 \cdot 8$ & $6 \cdot 1$ & 345 & $77 \cdot 3$ & I \\
\hline$(\mathrm{DV} G \times \mathrm{W} F \mathrm{~F} / 11)$ & $55 \cdot 7$ & 11.9 & $33 \cdot 4$ & 210 & $59 \cdot 9$ & II \\
\hline$(\mathrm{DV} G \times \mathrm{W} \mathrm{FS} / 4)$ & $48 \cdot 6$ & $17 \cdot 4$ & $34 \cdot 0$ & 432 & $58 \cdot 1$ & II \\
\hline$(\mathrm{DV} \mathrm{G} \times \mathrm{W} F \mathrm{FS} / 3)$ & $44 \cdot 8$ & $23 \cdot 5$ & $31 \cdot 7$ & 290 & $53 \cdot 7$ & II \\
\hline
\end{tabular}

TABLE 7

Percentages of total embryos and the corresponding estimate for the average percentage contribution of green plastids

Pure green shoots of variegated $F_{1}$ hybrids backcrossed to white $D$. Varden Hybrid: White F. of Spring female by green D. Varden male

\begin{tabular}{|c|c|c|c|c|c|c|}
\hline \multirow{2}{*}{$\begin{array}{l}\text { Sibs arranged in order of } \\
\text { percentage green plastid } \\
\text { contribution }\end{array}$} & \multicolumn{4}{|c|}{ Percentage embryos } & \multirow{2}{*}{$\begin{array}{l}\text { Percentage } \\
\text { green } \\
\text { plastids }\end{array}$} & \multirow{2}{*}{$\begin{array}{l}\text { Segregation } \\
\text { pattern } \\
\text { type }\end{array}$} \\
\hline & G & V & $\mathrm{W}$ & Total & & \\
\hline$(\mathrm{FS} \mathrm{W} \times \mathrm{GDV} / 3) \mathrm{G} \times \mathrm{WDV}$ & $96 \cdot 3$ & $3 \cdot 7$ & - & 217 & $99 \cdot 7$ & I \\
\hline$(\mathrm{FS} \mathrm{W} \times \mathrm{G} \mathrm{DV} / 6$ ) & $90 \cdot 4$ & $9 \cdot 0$ & 0.6 & 178 & $98 \cdot 2$ & I \\
\hline$(\mathrm{FS} \mathrm{W} \times \mathrm{G}$ DV $/ 7)$ & $77 \cdot 4$ & $22 \cdot 6$ & - & 186 & $97 \cdot 1$ & I \\
\hline$(\mathrm{FS} \mathrm{W} \times \mathrm{G}$ DV $/ 9)$ & $85 \cdot 6$ & $14 \cdot 4$ & - & 285 & $97 \cdot 0$ & I \\
\hline$(\mathrm{FS} \mathrm{W} \times \mathrm{G}$ DV $/ 8$ ) & $84 \cdot 4$ & $14 \cdot 0$ & $1 \cdot 6$ & 192 & $95 \cdot 7$ & I \\
\hline (FS W $\times$ G DV/11) & $76 \cdot 4$ & $21 \cdot 8$ & $1 \cdot 8$ & 55 & $94 \cdot 6$ & I \\
\hline$(\mathrm{FS} \mathrm{W} \times \mathrm{G} \mathrm{DV} / 2)$ & $73 \cdot 3$ & $25 \cdot 2$ & 1.5 & 202 & $93 \cdot 7$ & I \\
\hline$(\mathrm{FS} \mathrm{W} \times \mathrm{G} \mathrm{DV} / 10)$ & $79 \cdot 8$ & $19 \cdot 0$ & $1 \cdot 2$ & 168 & $92 \cdot 5$ & I \\
\hline$(\mathrm{FS} \mathrm{W} \times \mathrm{G} \mathrm{DV} / 12)$ & $58 \cdot 0$ & $41 \cdot 5$ & 0.5 & 217 & $90 \cdot 0$ & I \\
\hline$(\mathrm{FS} \mathrm{W} \times \mathrm{G} \mathrm{DV} / \mathrm{I})$ & $70 \cdot 0$ & $24 \cdot 7$ & $5 \cdot 3$ & 267 & $88 \cdot 2$ & I \\
\hline$(\mathrm{FS} \mathrm{W} \times \mathrm{G}$ DV $/ 4)$ & $60 \cdot 7$ & $36 \cdot 9$ & $2 \cdot 4$ & 206 & $88 \cdot 1$ & I \\
\hline$(\mathrm{FS} \mathrm{W} \times \mathrm{G}$ DV $/ 5$ ) & $66 \cdot 8$ & $23 \cdot 8$ & $9 \cdot 4$ & 202 & $84 \cdot 0$ & I \\
\hline
\end{tabular}

genotype. Of course, this does not mean that the presence of the plastid is irrelevant, simply that it appears to play a rather passive role in which the control of its transmission depends less upon the plastid itself, and rather more upon its nuclear environment, so that a change in the nucleus causes a change in the interaction between nucleus and plastids and a consequent alteration in the observed segregation frequencies. 


\section{Discussion}

The new evidence from inbred and hybrid lines confirms the existence of the type I $(\mathrm{G}>\mathrm{V}>\mathrm{W})$ and type II $(\mathrm{G}>\mathrm{V}<\mathrm{W})$ segregation patterns, except that with the type I pattern variegated were occasionally slightly more frequent than green. Within each of these two types there is a wide range of variation, but they do not overlap. The variation between individuals within each type is partly due to chance, but much of it is almost certainly genotypic, probably due to many genes with small effects since the variation is continuous, as far as can be judged at present.

Breeding experiments show that it is possible to analyse the genotype of the females because it is the genetic constitution of the female that determines which of the two segregation patterns is produced; varying the male can modify the pattern but does not produce a switch from one type to the other. Furthermore, as both patterns can occur with green female plastids of either cultivar, hypothetical differences between the plastids is not the determining factor. Control by nuclear genes is therefore probable, indeed the following observations are evidence for segregation according to the mendelian rule:

(1) The existence of a bimodal distribution into two patterns of plastid transmission without overlap strongly suggests a mendelian segregation and control with slight modifiers.

(2) When green $D$. Varden is the female parent in $G \times W$ crosses a type I pattern is produced, when green F. of Spring is the female parent a type II pattern is produced.

(3) When inbred, D. Varden is true breeding. When inbred, F. of Spring is not true breeding, instead approximately half the progeny produce the type I and half the type II pattern.

(4) The hybrids produced by crossing the two cultivars in any direction consist of a larger portion of type I and a smaller portion of type II plants.

Thus the cross between the true breeding D. Varden and the segregating F. of Spring is like a typical backcross between a homozygote and heterozygote, and like the backcross the progeny consist of two types of offspring, recognised by their type I or type II segregation pattern. Hence these results can be interpreted by the hypothesis that the type I pattern is produced under the control of one allele, and the type II pattern under the control of a second allele of a nuclear gene. As this proposed nuclear gene appears to control alternative patterns of plastid replication, and hence presumably has an effect on the replication of plastid DNA, I propose to symbolise it as $\operatorname{Pr}$ and the two alleles $\operatorname{Pr}_{1}$ and $\operatorname{Pr}_{2}$. Now, as $\mathrm{D}$. Varden is true breeding for the type I pattern its simplest genotype is therefore $\operatorname{Pr}_{1} \operatorname{Pr}_{1}$. Similarly, as F. of Spring contains the potentiality for producing both segregation patterns its simplest genotype is therefore $\operatorname{Pr}_{1} \operatorname{Pr}_{2}$.

Although the general observations support this hypothesis, the detailed results present a more complicated picture. According to the hypothesis, selfing $F$. of Spring is equivalent to selfing a heterozygote $-\operatorname{Pr}_{1} \operatorname{Pr}_{2} \times \operatorname{Pr}_{1} \operatorname{Pr}_{2}$, and this should give a genotypic ratio among the offspring of

$$
1 \operatorname{Pr}_{1} \operatorname{Pr}_{1}: 2 \operatorname{Pr}_{1} \operatorname{Pr}_{2}: 1 \operatorname{Pr}_{2} \operatorname{Pr}_{2} \text {. }
$$


The expected phenotypic ratio should be $1: 2: 1$ or $3: 1$. However, no category corresponding to $\operatorname{Pr}_{2} \operatorname{Pr}_{2}$ has yet been recognised as a distinct phenotype, and the observed ratio of type I:type II has a good fit with a $1: 1$ ratio $\left(\chi^{2}=0.4, P=0.7-0.5\right)$ in favour of type $I$ and not with a $3: 1$ ratio. The second anomaly arises when the two cultivars are crossed. We are actually making a nuclear backcross between a homozygote (D. Varden $\operatorname{Pr}_{1} \operatorname{Pr}_{1}$ ) and a heterozygote ( $F$. of Spring $\left.\operatorname{Pr}_{1} \operatorname{Pr}_{1}\right)$. Hence the progeny should consist of two genotypes in a ratio of $1 \operatorname{Pr}_{1} \operatorname{Pr}_{1}: 1 \operatorname{Pr}_{1} \operatorname{Pr}_{2}$ and on testing half should produce the type I and half the type II pattern. What we actually observed was not a $1: 1$ but a $3: 1$ ratio in favour of the type I pattern if we sum the overall results. But, as already noted, the four groups of hybrids tested (tables 4-7) were not all alike and their results should probably not be summed. On the contrary, I believe that the direction of the parental crosses really does have a very significant effect on the relative frequencies of the possible hybrid genotypes.

Although the results are numerically a little thin, there does appear to be enough circumstantial evidence to suggest that the anomalous data can be explained on the assumption that the $\mathrm{Pr}_{2}$ allele is semi-lethal, particularly when associated with the female parent, and particularly when associated with white plastids, so that one can draw up a tentative order of decreasing lethality as FS W $q>$ FS G $q>$ FS W $\hat{0}>$ FS G $\approx$. Let us now see how this hypothesis helps to provide a consistent explanation of the results :

(i) The $\mathrm{W} \times \mathrm{G} F$. of Spring nuclear self $\left(\operatorname{Pr}_{1} \operatorname{Pr}_{2} \times \operatorname{Pr}_{1} \operatorname{Pr}_{2}\right)$ ought to produce a $1: 2: 1$ or $3: 1$ ratio, but if the $\operatorname{Pr}_{2}$ allele is completely lethal in the white female parent the consequent result would be a ratio of

$$
1 \operatorname{Pr}_{1} \operatorname{Pr}_{1}: 1 \operatorname{Pr}_{1} \operatorname{Pr}_{2}
$$

corresponding to the observed segregation pattern of 1 type $I: 1$ type II (table 1).

(ii) The four hybrid crosses $\left(\operatorname{Pr}_{1} \operatorname{Pr}_{2} \times \operatorname{Pr}_{1} \operatorname{Pr}_{1}\right.$ and reciprocal) should all give a ratio of 1 type I: 1 type II pattern when their progenies are tested. In fact, they all give an excess of the type I pattern. In two crosses the heterozygote is the female parent. When this heterozygote carries white plastids there are no type II progeny at all (table 7), and when it carries green plastids there is only a single type II offspring (table 4). These results can again be explained on the assumption that the $\operatorname{Pr}_{2}$ allele is lethal on the female side in combination with white plastids, and semi-lethal in combination with green plastids. In the other two crosses the heterozygote is the male parent. When this heterozygote carries white plastids a quarter of the progeny are type II (table 6), although a half is expected, suggesting that the $\mathrm{Pr}_{2}$ allele is still at a disadvantage. Finally, when the heterozygote is the male in combination with green plastids the expected ratio of 1 type I: 1 type II progeny is almost reached (table 5), suggesting that there is no longer any serious lethality associated with the $\mathrm{Pr}_{2}$ allele.

(iii) The proposed hypothesis also explains why it is that the F. of Spring $\mathrm{W} \times \mathrm{G}$ cross produces a type I pattern and not a type II, because if the $\operatorname{Pr}_{2}$ allele is lethal only $\operatorname{Pr}_{1}$ eggs will be produced, and these will behave according to the type I pattern, whereas in the reciprocal $\mathrm{G} \times \mathrm{W}$ cross sufficient $\mathrm{Pr}_{2}$ eggs may survive to give the type II pattern. The same 
phenomenon has also been found in the hybrid (DV G $\times$ W FS/3) G $\times$ W self, which gave a type II pattern compared with (DV G $\times$ W FS/3) W $\times$ G self, which gave a type I pattern. No other cases have been investigated.

If the lethal or semi-lethal hypothesis is the correct explanation for the apparent deficit of the $\operatorname{Pr}_{2}$ alleles among selfs and hybrids there is still the question of when the selective process operates, but no obvious single answer. Selection against the $\operatorname{Pr}_{2}$ allele might occur in the choice of which of the four products of meiosis develops into the female egg, or the $\operatorname{Pr}_{2}$ allele might be associated with the known loss of many embryos prior to germination irrespective of their plastid content (Tilney-Bassett, 1970a), or the $\mathrm{Pr}_{2}$ allele might be lost with the final death of many white and some variegated seedlings, or selection may operate at all these stages.

The $\operatorname{Pr}_{2}$ allele tends to become lost during the crossing experiments, and yet its presence is necessary for the production of the type II segregation pattern. These two properties lead me to suggest that the two alleles, acting independently in the eggs, control the segregation pattern by the $\operatorname{Pr}_{1}$ allele favouring the multiplication of green plastids and the $\operatorname{Pr}_{2}$ allele the multiplication of white plastids in the zygote or early embryo. On this hypothesis the phenotype of each embryo is largely dependent upon the genotype of its initial egg, so that collectively the pattern type observed is determined by the distribution of genotypes amongst the eggs of one individual parent. Thus if the eggs are all of one genotype, $\operatorname{Pr}_{1}$, a type $I$ pattern results, whereas if about half the eggs are $\operatorname{Pr}_{1}$ and half $\operatorname{Pr}_{2}$ then collectively they will produce the type II pattern. Moreover, the control of plastid inheritance will seem to be by the female parent, as it is the female alone that produces the eggs and is responsible for the genotypes they contain. An unfortunate consequence of this proposed control mechanism is that most, and perhaps all, $\operatorname{Pr}_{2} \operatorname{Pr}_{2}$ homozygotes would occur among the white embryos which die before or shortly after germination; this would certainly explain why such homozygotes have not been recognised as they would not have been included amongst the variegated plants chosen for testing. Support for independent allelic activity in eggs comes from the observation that the D. Varden male always raises the frequency of variegated embryos, but not white ones, compared with the F. of Spring male. This indicates that the action of the gene in controlling plastid replication is capable of some modification in the zygote, hence the segregation pattern is not entirely decided before fertilisation. The effect shows that the D. Varden male allows more plastids to be transmitted or its nucleus raises the chance of male plastids multiplying in synchrony with the female ones, but not at their expense.

Further experiments are needed to confirm the ideas presented in this discussion or, if to reject them, then to seek new explanations. Nevertheless, whatever the future outcome, the present results clearly demonstrate the importance of the nuclear genotype in controlling the pattern of plastid inheritance. Pelargonium may be a special case, but we must also consider that the variations in the extranuclear plastid inheritance in other species could also be under nuclear control and that examples of purely maternal inheritance may be due to the failure of male plastids to replicate rather than their failure to enter the egg as is usually assumed. Biparental plastid transmission might therefore be achieved in other species simply by selecting 
females with suitable genotypes. Finally the possible role of nuclear genes in controlling the replication of organelles in general has implications for all studies of organelle genetics, and is a field of enquiry that needs further investigation in other species.

Acknowledgments.-I particularly wish to thank Miss Jenny Hargrave who made about one-tenth of all the crosses and whose results are indistinguishable from my own. I should also like to thank Miss Susan Leonard and Mrs Paramjit Kaur for their assistance with parts of the crossing programme.

\section{REFERENGES}

Tilney-bassett, R. A. E. 1970a. Genetics and plastid physiology in Pelargonium. III. Effect of cultivar and plastids on fertilisation and embryo survival. Heredity, 25, 89-103.

tilney-BAssetr, R. A. E. 1970b. The control of plastid inheritance in Pelargonium. Genet. Res. Camb., 16, 49-61. 